\title{
JOVENS DIANTE DA HISTÓRIA: o nacional e o internacional na América Latina
}

\author{
YOUTH IN THE FACE OF HISTORY: national \\ and international agendas in Latin America
}

\author{
Luis Fernando Cerri* \\ Jonathan de Oliveira Molar**
}

\begin{abstract}
Resumo
O presente artigo tem por objetivo analisar distintos aspectos político-identititários das noções de consciência histórica, cultura política e nação, de alunos com 15 anos de idade de três países vizinhos: Brasil, Argentina e Uruguai. Este trabalho está inserido em um contexto mais amplo do projeto, denominado "Jovens diante da História", que buscou inspiração em uma experiência de pesquisadores europeus chamada "Youth and History", iniciada em 1994. Com base em um questionário com mais de 40 questões direcionadas a alunos e professores dos países abarcados no projeto, selecionaram-se algumas situações em que os alunos abordaram assuntos ligados aos objetivos desse recorte temático. Consideram-se, assim, a partir das assertivas dos respondentes, assuntos que discutem desde o passado colonial latino americano a dilemas da contemporaneidade como entraves entre nações e blocos econômicos.
\end{abstract}

Palavras-chave: Cultura política. Identidades. América Latina. Nacional/Internacional.

\begin{abstract}
The present article aims at analyzing different political-identitary aspects of the notions of historical consciousness, political culture and nation of 15 year old students from three neighboring countries: Brazil, Argentina and Uruguay. This work is part of the project called "Jovens diante da História", which sought inspiration in an experience conducted by European researchers called "Youth and History", started in 1994. Based on a survey with more than 40 questions directed to students and teachers of the studied countries, a number of situations were selected in which the students approached topics related to the goals of the research. Therefore, from the assertions of the respondents, the present article considers issues that deal with both the colonial past of Latin America and the contemporary dilemmas, such as hindrances between nations and economic blocs.
\end{abstract}

Keywords: Political Culture. Identities. Latin America. National/International Agendas.

\section{Introdução}

O presente artigo visa discutir aspectos político-identitários que envolvem noções de consciência histórica, cultura política e nação, a partir de uma pesquisa empírica com alunos com 15 anos de idade, provenientes do Brasil, Argentina e Uruguai, no contexto do projeto de pesquisa intitulado "Jovens diante da História”. O questionário utilizado para os alunos envolveu mais de 40 questões das quais foram selecionados para este texto os dados que abarcavam as noções citadas acima. O questionário dos professores não continha informações sobre esses temas.

O primeiro elemento que se torna necessário considerar é o problema da pesquisa empírica da consciência histórica em função do conceito de consciência histórica. Embora o uso do termo esteja relativamente generalizado nos meios da pesquisa em ensino de História, da formação de professores e das políticas públicas para o ensino de História, consciência histórica não tem uma definição unívoca. Cardoso (2008) lista quatro sentidos possíveis para o tema na literatura especializada.

Em estudo anterior, Cerri (2001) indica que há duas grandes vertentes na abordagem do conceito: a primeira (inclusive cronologicamente) estabelece que a consciência histórica é o resultado de condições de ambiente histórico e cultural e de preparação intelectual do indivíduo, de modo que ele se torna capaz de conceber a condição histórica de todas as coisas e agir de modo consciente sobre elas, considerando a relatividade de todos os discursos e opiniões.

\footnotetext{
*Professor do PPGE/UEPG. E-mail: Ifcronos@yahoo.com.br

*** Mestre em Educação e professor colaborador da Universidade Estadual de Ponta Grossa - UEPG. E-mail: jonathanmolar@hotmail.com
} 
Outra vertente da abordagem do conceito de consciência histórica a considera como um conjunto de estruturas mentais e processos, típica do pensamento humano, necessária à vida cotidiana, independentemente do contexto em que se insira. Para Rüsen (2001, p. 57), a consciência histórica pode ser descrita como "a suma das operações mentais com as quais os homens interpretam a sua experiência de evolução temporal de seu mundo e de si mesmos, de tal forma que possam orientar, intencionalmente, sua vida prática no tempo".

Ambas as vertentes contém conceitos a partir dos quais é possível realizar levantamentos empíricos de elementos constituintes da consciência histórica. Para a primeira, entretanto, isso seria de pouco interesse, já que as características e componentes desse fenômeno já são dadas no próprio conceito. Também para essa vertente, a pesquisa teria a desvantagem de limitar levantamentos interculturais, pois seriam excluídas as culturas em que a consciência histórica não fosse uma característica marcante. Pelo mesmo motivo, não seria possível uma coleta de dados abrangente dentro de uma mesma sociedade, visto que nem todos reuniriam os quesitos educacionais e culturais necessários para serem tomados como portadores de consciência da História. Isso pode ser problemático até mesmo nas sociedades europeias que, após décadas de migrações vindas do Terceiro Mundo, apresentam-se como sociedades multiétnicas e multiculturais.

A vertente representada por Rüsen, Bergmann, Heller e outros sustenta a possibilidade da realização de surveys internacionais e interculturais. Tanto é assim que a investigação "Youth and History", por exemplo, que inspirou a pesquisa cita em seu relatório final 11 obras de Jörn Rüsen. (ANGVIK; BORRIES, 1997).

A pesquisa sobre consciência histórica está intimamente ligada às preocupações quanto às atitudes políticas dos respondentes, cidadãos plenos ou em via de chegarem a essa condição ao completar a maioridade legal. Em muitos casos, os alunos respondentes estão prestes a realizar sua primeira participação política como eleitores, uma vez que no Brasil o direito ao voto já está disponível (embora ainda não obrigatório) aos 16 anos de idade.

Para enfrentar esse aspecto da questão geral, utilizamos o conceito de cultura política, que "referese às orientações especificamente políticas, às atitudes com respeito ao sistema político, suas diversas partes e o papel dos cidadãos na vida pública", segundo Almond e Verba (1989 apud BORBA, 2005, p. 148). De acordo com o cientista político José Álvaro Moisés, há um consenso quanto a esse conceito, que envolve "a generalização de um conjunto de valores, orientações e atitudes políticas entre os diferentes segmentos em que se divide o mercado político e resulta tanto dos processos de socialização, como da experiência política concreta dos membros da comunidade política". (MOISÉS, 1992, p. 7).

Desse modo, no projeto "Jovens diante da História”, busca-se as articulações entre a cultura histórica - conceito que delineia "um conjunto de fenômenos histórico-culturais representativos do modo como uma sociedade ou determinados grupos lidam com a temporalidade (passado-presentefuturo) ou promovem usos do passado" (ABREU; SOIHET; GONTIJO, 2007, p. 15) - e cultura política. Para Flores (2007), expressão cultura histórica expressa a perspectiva de articulação entre processos históricos em si e os processos de produção, transmissão e recepção do conhecimento histórico, o que é perfeitamente compatível com os objetivos que se estabeleceu para a investigação.

\section{Metodologia, inspiração e histórico}

Antes da incorporação de dados do Uruguai, o projeto se chamava "Jovens brasileiros e argentinos diante da História" e foi inspirado basicamente na pesquisa "Youth and History", desenvolvida nos países europeus a partir de 1994, com base na rede European Standing Conference of History Teachers Associations (Euroclio). Esse projeto procurou dar respostas às questões sobre a qualidade, as características e os resultados do ensino de História, bem como sobre a configuração geral da consciência histórica e atitudes políticas dos jovens europeus, por meio de um levantamento comparativo de amplo alcance. A pesquisa foi realizada através de um questionário fechado respondido por jovens de 15 anos, que versava sobre conteúdos, métodos e concepções de História e cidadania, com sustentação no conceito de consciência histórica. Constituiu-se da elaboração, aplicação e tabulação dois questionários: um para alunos e outro para professores, definidos após várias reuniões entre as dezenas de pesquisadores de toda a Europa, liderados por Magne Angvik e Bodo von Borries. ${ }^{1}$

As adaptações para um projeto latino-americano referente à juventude e sua consciência histórica, que é o objetivo final desta pesquisa, envolveram, além da retradução a partir do português de Portugal, a adaptação cultural dos questionários, por meio de exclusão de algumas questões, inserção de outras e adaptação de outras ainda.

\footnotetext{
${ }^{1}$ Há uma descrição sumária do projeto e seus resultados em http://www.erzwiss.uni-hamburg.de/Projekte/Youth_and_History/ homepage.html. No Brasil, Schmidt e Garcia aplicam o conceito de consciência histórica em experiências de sala de aula com base em materiais de acervo familiar em escolas de Curitiba e região metropolitana. Outro estudo é a dissertação de mestrado de Maria Rosa Chaves Künzle, defendida no Programa de PósGraduação em Educação da Universidade Federal do Paraná em 2003, intitulada "O ensino de história e o conceito de nação: um instrumento de pesquisa".
} 
Foi incluída uma série de questões pertinentes para o contexto sul-americano, não contempladas satisfatoriamente no questionário europeu: os heróis nacionais (canônicos e subversivos), as ditaduras militares, o papel das mulheres. A questão sobre indenizações aos países colonizados foi modificada para indenizações aos descendentes dos povos originários ou africanos, explorados e/ou submetidos a políticas de extermínio no processo de construção das nações latino-americanas.

Os questionários - um para professor e um para alunos - incluem temas sobre os quais os respondentes manifestam-se marcando o nível de sua concordância com as afirmativas através da escala de Likert. ${ }^{2}$ Foram computados 1.472 questionários de alunos, sendo 744 do Brasil, 535 da Argentina e 193 do Uruguai, e mais 65 questionários de professores. ${ }^{3}$

\section{Identidade, nação e Mercosul: elos de uma mesma cadeia}

O entendimento moderno do conceito de nação advém da formação dos Estados Nacionais europeus, tendo inicio com a consolidação de Portugal

\footnotetext{
${ }^{2}$ A escala de Likert ou escala de atitudes é "uma maneira de medir como as pessoas vêem alguma coisa, seja um grupo de pessoas, uma questão social ou uma experiência de vida [...] os pesquisadores elaboram uma escala fazendo aos respondentes certo número de perguntas, todas elas relacionadas com a questão em pauta e que os convida a concordar ou discordar de declarações [...]." (JOHNSON, 1997, p. 87). No caso em questão elaboramos cinco níveis de concordância (variando de péssimo a ótimo, discordo totalmente a concordo totalmente e assim por diante), a partir da qual se atribui valores numéricos a cada resposta (de -2 para a resposta mais negativa, passando por zero para as respostas neutras e 2 para a resposta mais positiva), sendo que o tratamento é a produção de médias que permitem aferir a concordância média com cada afirmação, e a definição de desvio padrão, que permite conhecer a média da variação das respostas. As questões para os alunos envolvem opiniões sobre o significado da história, a importância de seus objetivos, formas de História que mais agradam e em quais mais se confia, importância de religião e política, as práticas de sala de aula, conhecimentos de cronologia sobre processos históricos, interesse em períodos e temas de História, noção de passado e projeções para o futuro (pessoal e coletivo), tópicos importantes do conteúdo escolar da História (Idade Média, Colonização, Revolução Industrial, Adolf Hitler), grau de importância de elementos da vida pessoal e coletiva, sentido da História, interpretação da riqueza e pobreza, compreensão da historicidade, definições de nação, solidariedade social, próceres, Mercosul, democracia, papel da mulher, governos militares e posicionamento quanto a temas polêmicos contemporâneos.

${ }^{3}$ As cidades envolvidas incluem Ponta Grossa, Curitiba, Londrina, Cornélio Procópio, Marechal Cândido Rondon, Cascavel e Francisco Beltrão (todas no Paraná), La Plata, Santa Fe, Malvinas Argentinas, San Miguel, e José C. Paz (na província de Buenos Aires, Argentina), Montevidéu, Solymar e Florida (no Uruguai). Em todas as cidades foram selecionadas cinco escolas (quando havia todas as categorias): três públicas (central, de periferia, de excelência) e privada (confessional e laica). Não se tratam de amostras estatísticas, mas de um ensaio de aplicação do instrumento. As conclusões, portanto, não são dadas em termos de representatividade nacional, mas de indícios para a continuidade da investigação e da reflexão, o que não torna os resultados menos significativos.
}

e Espanha a partir do século XV. Contudo, a ideia de que a nação é a união entre o ideal de soberania, povo e território, iria se formar durante o século XVIII com a política do Estado-Nação (de homogeneização cultural e fortalecimento das fronteiras territoriais e identitárias). Dessa forma, uma nação surge alheia à vontade de um soberano, concepção que não seria viável no século $X V$, destarte que para a construção nacional há uma série de fatores que geram sua fundação e, principalmente, manutenção. (IANNI, 1999).

As questões étnicas, religiosas ou linguísticas são fatores relevantes, mas não suficientes para a formação de uma nação, que depende também de sua representação nas três temporalidades, isso é, passado, presente e futuro. As lembranças do passado através da memória e outras formas de resgate, atreladas ao presente e ao desejo de convivência em comum e, por último, o futuro e o desejo de desenvolvimento e de manutenção de seu cimento identitário.

Segundo Poutignat e Streiff-Fenart (1998), a nação em seu sentido moderno difere, seja como Estado, seja como conjunto de pessoas que aspiram à formação de um Estado, das comunidades às quais as pessoas se identificam tradicionalmente, em extensão, em número e em natureza. Apesar disso, as nações procuram oferecer vínculos com a tradição e as perspectivas vindouras, conforme explicita o hino esparciata: "Nós somos o que vocês foram; nós seremos o que vocês são". (RENAN, 1882/2006, p. 19). Contudo, a ordem neoliberal global lança uma nuvem nebulosa sobre as fronteiras das nações e ao entendimento dos seus componentes básicos, dificultando assim, a orientação temporal, função da consciência histórica.

Agregada à ideia de nação encontra-se o conceito de identidade, o qual permite que um indivíduo se localize em um sistema social e seja localizado por esse; e, mais amplamente, realiza a identificação de uma comunidade. A noção de identidade há muito vem se modificando. Atualmente, têm-se o que Stuart Hall (1999) chama de a "crise da identidade", ou seja, um processo amplificado de modificações, em que as estruturas e processos centrais são deslocados, abalando os quadros que forneciam uma referência estável aos indivíduos no mundo social. Desses, as ideias de povo e soberania são consideradas essenciais, mas, assim como a ideia de território, são recolocadas dentro das formas fluidas da contemporaneidade, que envolvem deslocamentos populacionais expressivos para outros países, entre outros fenômenos.

O século $X X I$ encontra consolidada a ordem multipolar no sistema mundial (HALL, 1999). Em outras palavras, apesar da persistência da divisão dicotômica entre desenvolvidos/ subdesenvolvidos há possibilidades de agrupamentos entre países, seja por 
fatores econômicos, políticos ou sociais. Nesse contexto, os grandes blocos como a União Europeia, Mercosul, Nafta, e outros ganham um novo significado.

O Mercosul deu início a um processo de integração entre seus membros e vem se ampliando com a perspectiva em curto prazo de ingresso de demais países como Chile e Venezuela. Para além da importância econômica para seus membros, o bloco é também um instrumento de política internacional.

O significado internacional do Mercado Comum depende, por um lado, de uma política comum satisfatória e integradora e, por outro, das alternativas expostas pelos jogos de interesses da ordem mundial. Dentre os principais pontos que compõem os objetivos do Mercosul, a integração comercial é a que se encontra mais avançada, vislumbrando-se a curto prazo a integração aduaneira e a livre circulação de bens, serviços, capital e mão de obra. São previsíveis os conflitos por medidas protecionistas; essas, contudo, podem ser consideradas mínimas frente ao todo.

Em suma, o Mercosul tornou-se uma importante ferramenta para lidar com a globalização e o sistema multipolar, intensificando a competitividade de seus membros no mercado internacional, viabilizando não só o desenvolvimento econômico, mas social de forma geral. Porém, cresce a percepção de que a integração econômica não é estável nem duradoura se não for acompanhada de uma crescente integração cultural e educacional resultante de esforços crescentes por parte dos governos e quadros da ciência e da cultura dos países membros. É nesse contexto que se encontra essa pesquisa.

\section{Jovens diante da História: política, nação e consciência histórica}

A questão de número 32 do questionário envolvia uma disputa hipotética entre a nossa nação (A) e outra (B) sobre a região de "Terranova"; situação essa, aliás, encontrada com grande frequência na atualidade. Essa questão foi traduzida diretamente do questionário europeu. Nas alternativas, além de permitir entrever que tipo de solução os respondentes imaginam para o conflito, se evidenciam algumas das representações que constituem a noção de nação: na verdade, as alternativas postas para os alunos referem-se a modos de definir a nação. Assim, ao responder, os sujeitos aplicam o conceito que têm, além de demonstrá-lo.

A concepção predominante na amostra trabalhada distancia-se de uma concepção tradicional, que defende a nação como resultado natural da cultura de um povo, ou seja, as nações já estariam dadas por forças culturais e mesmo étnicas e telúricas, antes mesmo de sua efetiva existência histórica (a título de exemplo, essa concepção está presente no livro "Geopolítica do Brasil", do mentor da ditadura militar, Golbery do Couto e Silva).

Percebe-se isso quando uma língua comum, uma cultura comum e um extenso tempo de convivência tendem a não ser suficientes, para os respondentes, para que um território e um povo pertençam a uma nação e sejam anexados por ela. Ao mesmo tempo, é perceptível uma grande credibilidade e apelo para as soluções negociadas para conflitos internacionais.

Um dos dados mais significativos é a vontade dos habitantes, que aparece em média como o fator mais importante para que um território faça parte de uma nação. Diante desses dados, fica caracterizada a predominância de uma concepção política de nação, que a entende como o resultado de um contrato, de uma adesão a um projeto coletivo, em vez de uma decorrência natural da terra, da etnia ou da língua, que dispensasse a decisão voluntária dos seus integrantes. Outro dado importante é que, embora os estudantes brasileiros acompanhem todas essas perspectivas, suas médias são ligeiramente mais baixas que as dos colegas uruguaios e argentinos.

Pode-se perguntar se o resultado seria igual caso nos referíssemos a conflitos reais, como no caso emblemático das Malvinas, por exemplo, para os argentinos. Ou, ainda, sobre os efeitos do Brasil não ter demandas territoriais com outros países desde o início do século passado.

Dentre as opções para solucionar o impasse, os alunos que participaram da pesquisa escolheram a arbitragem como alternativa mais apropriada, seguida de perto pela ideia de que a escolha da Terranova deveria ficar a cargo dos habitantes da citada região, apontando para o viés da soberania popular, inspirado na vertente iluminista e na perspectiva do contrato social de Rousseau. Com menor intensidade, o fator cultural também foi apontado como critério para solucionar a questão, mas com um nível mais baixo de concordância, próximo do fator histórico, o tempo de permanência de nossos colonos ou nosso controle político do território. De forma mínima, os alunos apontaram a força militar como solução.

Destaca-se nessa questão a escolha dos alunos por meios pacíficos e democráticos para a decisão do citado conflito territorial, seja por acordos internacionais ou pela soberania popular dos habitantes de Terranova. Enfatiza-se também, a opção pelos caracteres culturais e geográfico-históricos, denotando assim, o interesse pelo conceito moderno de nação - soberania, território e povo. Em um mundo fragmentado (BAUMAN, 2005) e sacudido por ondas violentas (tanto a nível micro quanto macro), essa rejeição por parte dos alunos é como um farol em um oceano escuro. 
32. Suponha que Terranova foi ocupado pelo nosso país (A) de 1500 a 1900. De 1900 até hoje, Terranova foi ocupada pelo país B. Nosso país quer Terranova de volta e apresenta argumentos. Que importância você dá aos seguintes argumentos:
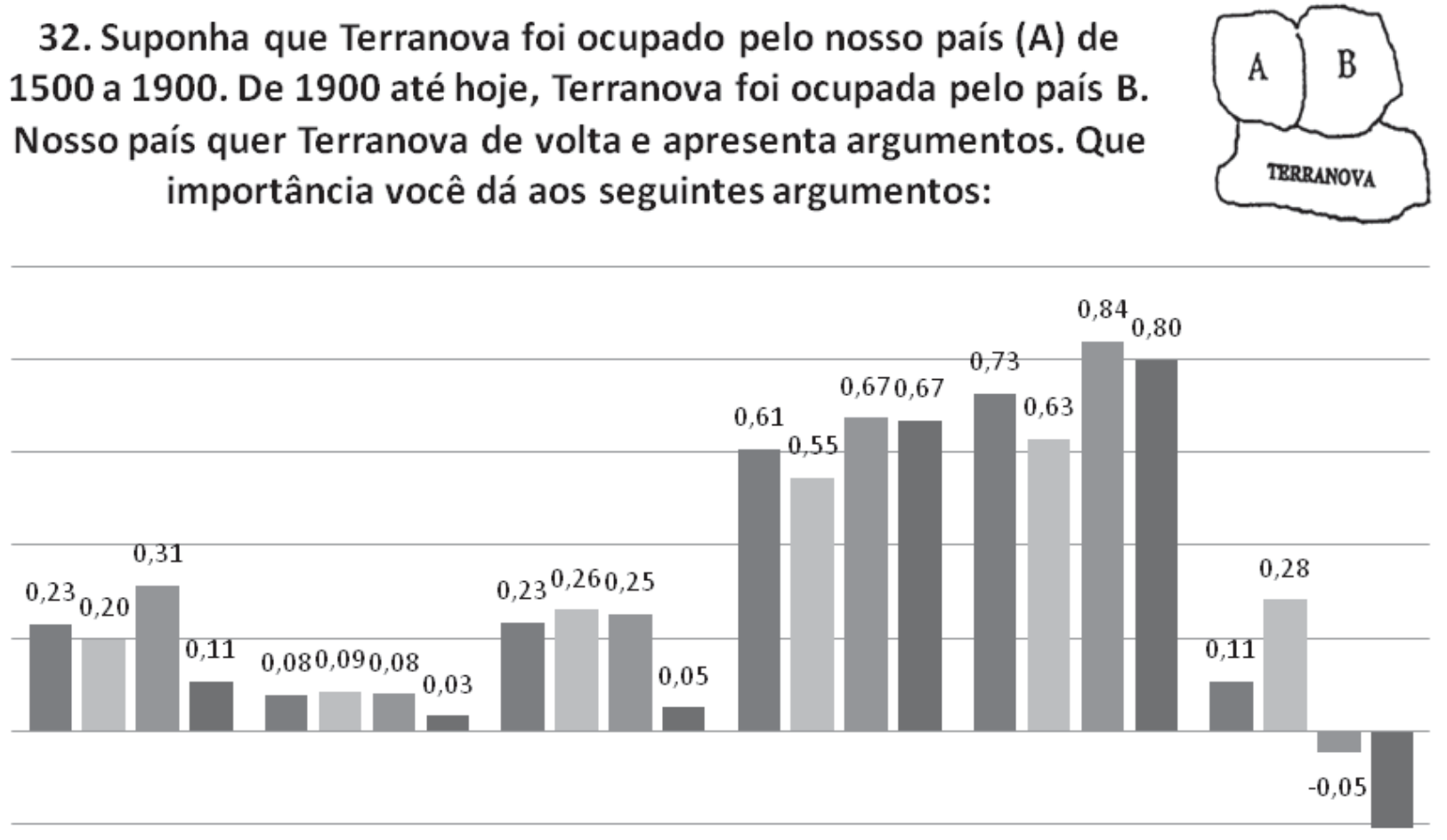

$-0,21$

\section{a. "O povo de}

Terranova fala nossa esteve mais tempo

língua e têm nossa sob nosso controle cultura"

\begin{abstract}
do que de $B$
\end{abstract}
c. "Os colonos do nosso país se estabeleceram em Terranova em 1500 enquanto os do país B só a partir de $1900^{\prime \prime}$ d. "Quando perguntados os habitantes de Terranova dizem que preferem viver sob nosso controle do que sob o controle de B e. "Um encontro f. "Nós temos poder internacional depaz militarefaremos examinou o caso e uso dele para ter reconheceu o Terranova de volta direito do nosso país de ter Terranova de volta"..

\section{Média Aritmética Brasil argentina $\square$ Uruguai}

Figura 1. Questão 32 do Questionário

Fonte: Dados do Projeto "Jovens diante da História" - 2009

A análise particular de cada país não destoa sobremaneira da média geral, mas podemos encontrar algumas particularidades, como o apoio mais intenso entre os alunos brasileiros à utilização de vias militares, que obtiveram índice superior às alternativas cultural e histórica; ainda assim, prevaleceram os meios pacíficos com base no diálogo internacional.

Dessa forma, apesar dos três países participantes apresentarem um passado colonial, os dados fornecidos pelos alunos brasileiros inferem menor apego às questões culturais e geográficas, o que pode resultar de marcas mais dolorosas de um pacto colonial com forte peso escravista, que pouco agregou a uma visão de nação como soberania popular e identificação com o território.
$\mathrm{Na}$ Argentina, atenta-se para a elevada ênfase a arbitragem internacional com e pela escolha popular dos "terranovenhos". Além disso, verifica-se que a questão cultural é aceita de modo mais expressivo como critério de nação vista de forma intensa, encontrando-se acima do geral; confirmando a tendência de solucionar conflitos por meios pacíficos, a opção militarista aparece com -0,5. No caso uruguaio, visualiza-se tendência similar ao argentino dentre as opções de cunho pacífico, obtendo os maiores valores de concordância com a soberania popular como critério pelos alunos. Singularmente, encontra-se pequena ênfase à questão cultural, a menor média entre os três países, porém com os maiores índices de repúdio pelas vias militares. 


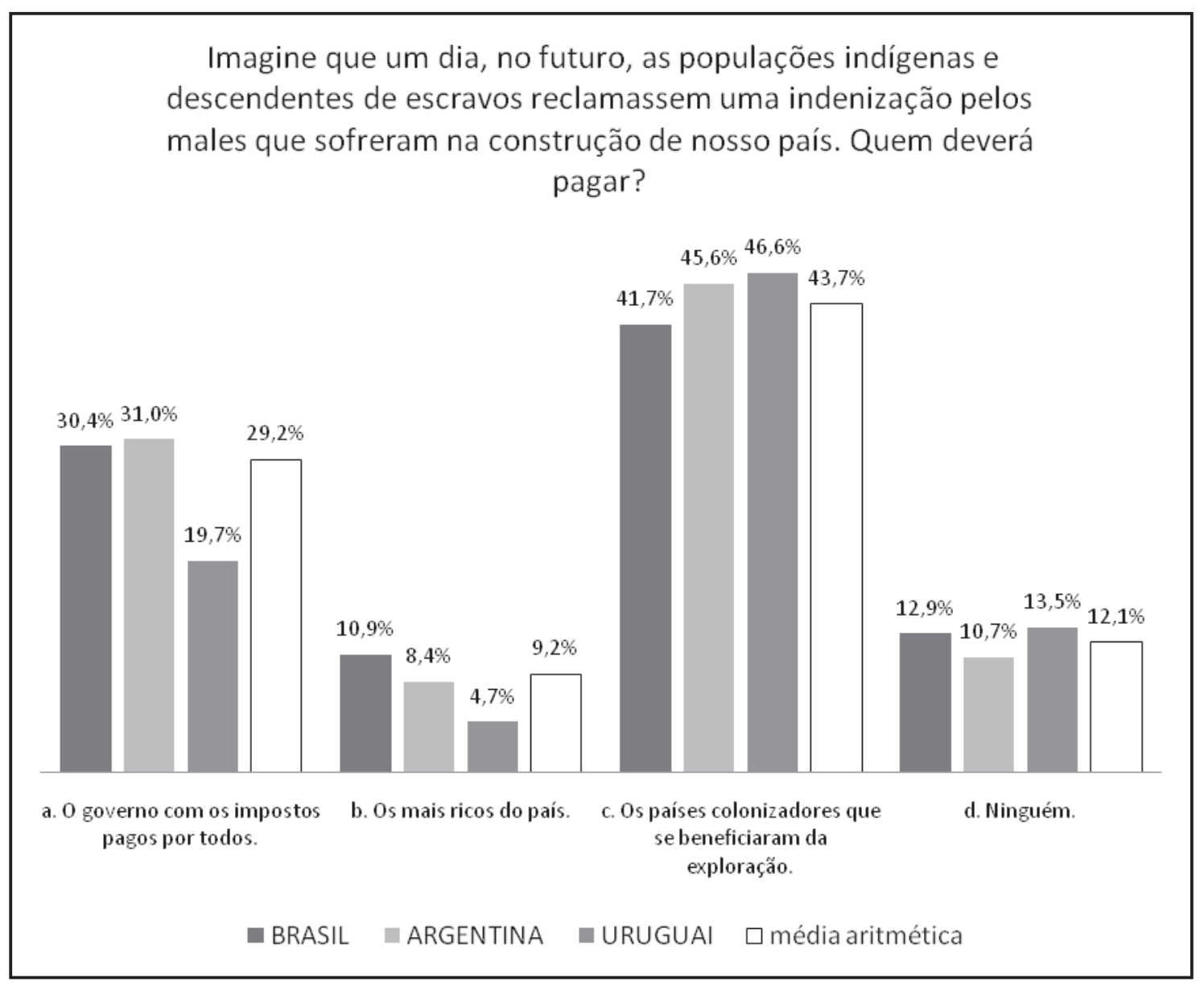

Figura 2. Questão 34 do Questionário

Fonte: Dados do projeto "Jovens diante da História" - 2009

A questão 34 não usou a escala de Likert, mas a escolha de uma opção entre as oferecidas. Essa pergunta colabora com o esboço da definição de nação que os estudantes assumem, porque ajuda a caracterizar as relações internas que se imagina na comunidade nacional, diante da noção de uma "dívida histórica" a solucionar para conciliar ou mitigar as diferenças sociais e seus efeitos danosos nas relações.

Esse extenso grupo ao qual pertencemos é estruturado por diferenças sociais e econômicas que são vinculadas ao passado comum que, por sua vez, também nos identifica, e coloca a identidade em crise: se participamos da nação para que todos se beneficiem, e a própria História da construção da nação prejudicou alguns através da exploração, então o pacto se fragiliza: se a desigualdade que causamos não é ao menos combatida, a comunidade perde sua credibilidade e meu benefício pessoal ao participar dela também está ameaçado. Com a formulação que demos à questão, introduzimos um dado substancialmente novo em relação à pergunta do questionário europeu, porque ela não pressupõe necessariamente uma divisão interna e uma crise de identidade nacional a resolver.
Com $47 \%$ na estimativa geral, os colonizadores europeus, segundo os alunos, deveriam arcar com a indenização. Dessa forma, prevalece a questão histórica de um passado colonial latino-americano. Passado doloroso, aliás, não só para negros e indígenas, mas também, conforme aponta a pesquisa para os colonizados de forma geral.

A segunda opção mais votada refere-se ao Estado como o responsável para o pagamento da indenização, através dos impostos (29\%). Infere-se, com isso, a visão do Estado enquanto ente hegemônico, organizador da sociedade, que tem como dever amenizar as injustiças históricas.

Outra interpretação possível, diante do esclarecimento de que o Estado age "com os impostos pagos por todos" é a perspectiva do assumir coletivo de responsabilidade, postura consequente com a solidariedade interna das comunidades nacionais. Em outras palavras, é o conjunto da sociedade cujo passado comum se sustenta na desigualdade que deve se responsabilizar por atitudes que promovam igualdade. A consequência política na base dessa posição é uma visão não liberal e tendencialmente socialista (no sentido amplo), presente em quase um 
terço da amostra brasileira e argentina e em pouco menos de um quinto da amostra uruguaia.

A alternativa de que "ninguém" deveria pagar a indenização obteve $15 \%$ do total, assim, parte-se de uma noção que se desvincula do passado e rejeita a demanda de reparação dos grupos prejudicados nos processos iniciais de construção da riqueza nacional; em $10 \%$ dos casos, os alunos atribuíram aos ricos o dever de arcar com a indenização, um índice baixo e que indica a dissolução do elo entre classe social e questões históricas.

A escolha do Estado como responsável denota uma visão legalista e soberana do ente público, ou seja, o gestor que deverá suportar a sociedade em seus diversos níveis, até mesmo, pelo Estado atual ter se dado por desdobramentos de um passado coIonial. A tendência predominante, entretanto, é a de "exportar" a dívida histórica. Nesse caso, embora se assuma o pleito da reparação, a responsabilidade por saldá-la é exportada para os países colonizadores, o que pode significar, novamente, uma operação da cultura política que visa reconhecer a demanda para não colocar a comunidade nacional num impasse, mas protelando-a de modo que não seja resolvida ou que sua resolução não implique qualquer alteração, ainda que mínima, do status quo.
Ainda nesse campo, pode expressar uma fórmula muito comum nos países latino-americanos, que atribui à exploração estrangeira e/ou ao imperialismo o conjunto das desgraças nacionais, adiando a redenção do país para o incerto futuro em que essa exploração acabe. Trata-se de uma manobra populista, pois inclui e legitima a demanda dos pobres, mas sem exigir dos ricos a partilha da sua riqueza. Ambas as posturas podem ou não estar embasadas em uma deficiente aprendizagem da História, pois o ensino dos períodos coloniais pode ter levado à noção de que apenas os estrangeiros se beneficiavam da relação econômica desfavorável com a metrópole, não havendo espaço na fórmula para o papel das elites locais.

Quanto à análise particular de cada país envolvido na pesquisa, não se verificam distinções acentuadas nessa questão.

Ao serem indagados na questão 36 sobre a noção do que seria um país/nação, os alunos revelaram uma visão paradigmática reduzida: 0,56 de índice médio dos participantes afirmaram que se deveriam defender com todos os meios possíveis os interesses de um país. Embora não seja explícito, apreende-se que, inserido nessa alternativa, há o envolvimento de ferramentas militares e perspectivas de agressão, mas o esclarecimento completo disso demandaria uma pesquisa qualitativa.

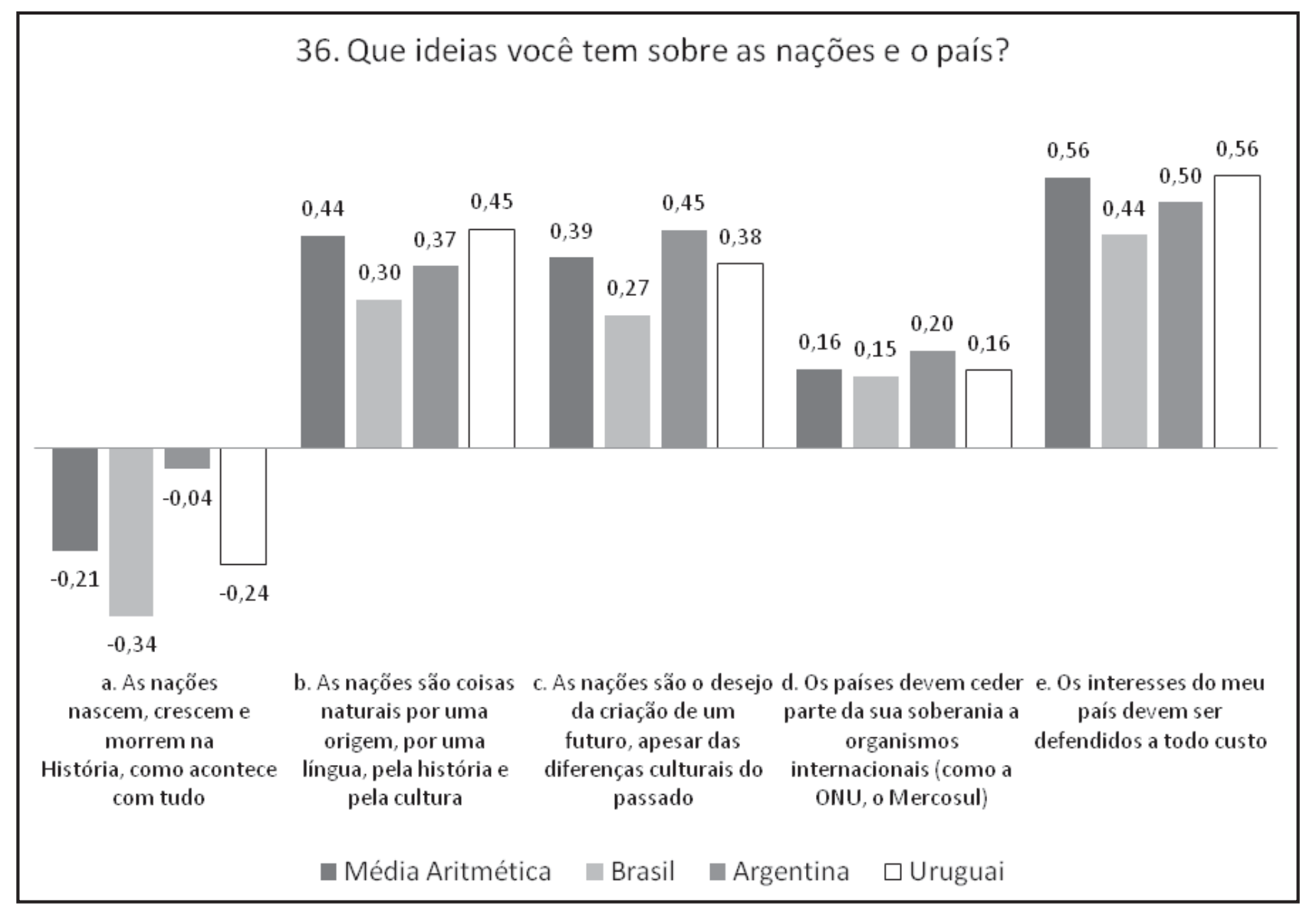

Figura 3. Questão 36 do Questionário

Fonte: Dados do Projeto "Jovens diante da História" - 2009 
No que se refere à descrição do conceito propriamente dito, os alunos entendem um país enquanto união natural de indivíduos ou grupos ligados pela língua e a cultura. Desse modo, apesar das questões linguística e cultural serem de extrema importância para o laço identitário, a formação de um país em sua gênese histórica, política e econômica dá-se também por mecanismos mais amplos que não só as naturais pelo caráter linguístico-cultural. $\mathrm{O}$ país enquanto desejo de futuro e de reconhecimento do passado obteve 0,39 de média, com isso, essa alternativa está relacionada a um entendimento histórico de país/nação ao conectá-lo com as distintas temporalidades e que agrega passado/presente e futuro em uma mesma opção. A noção do país como cessão de soberania dos indivíduos para o Estado e que leva novamente a vertentes com origem rousseauniana, obteve baixo índice nessa questão - diferentemente na de número 32, o que talvez possa ser explicado pela formulação do item e de como ele foi decodificado pelos respondentes.

Das várias vertentes possíveis, fica claro que a da nação concebida como um fenômeno natural, intemporal, derivado do próprio tempo e com poucas chances de ser outra coisa além do que é, vertente essa de origem Romântica, equivalente, diante da amostra, à vertente que engloba as definições de nação como resultado de um acordo político constante e continuamente refeito entre os cidadãos. Essa última ideia, por sua vez, é de origem lluminista e pode ser descrita como tendo por centro a noção de política, enquanto a outra vertente está centralizada na noção de cultura. ${ }^{4}$

As vertentes culturais estão associadas ao item "b", enquanto as vertentes de predominância política estão associadas ao item "c". Para o Brasil, há uma leve tendência à predominância da "nação política", o oposto do que ocorre na Argentina, em que há uma leve tendência a favor da "nação cultura", que são praticamente iguais na amostra uruguaia.

Um dado interessante a notar é que, dos três países, a Argentina é o que mais coloca em discussão seu passado recente na esfera pública, além de ser aquele em que mais parece haver adesão a uma perspectiva cultural de nação; o que pode parecer contraditório, mas certamente merece um aprofundamento em novas pesquisas, tanto para consolidar esse dado quanto para esclarecer essa aparente contradição.

\footnotetext{
${ }^{4}$ Guyon et al. (1993) diferenciam essas vertentes associandoas ao modelo de nação da Alemanha (romântico e culturalista) e ao modelo de nação francês (iluminista e político). Optamos, entretanto por não usar essa categorização, pois se origina em um contexto de embate entre os dois países e não tem necessariamente uma correspondência na realidade atual. Ambas as vertentes, em múltiplas variações, são encontradiças em ambos os países e nas demais nações do globo.
}

É possível perceber ainda certo sucesso do discurso nacionalista, que procura projetar a nação como atemporal, na tendência à rejeição do item a, que indica a nação como fenômeno com início, meio e fim. Por fim, os itens "d" e "e" são complementares e indicam que os respondentes tendem a valorizar a soberania nacional e os interesses do próprio país. Em resumo, é uma tarefa complexa analisar os números coletados no Brasil e na Argentina, pois as escolhas dos alunos podem ser lidas como uma série de aparentes contradições. Seja nas opções de cunho tradicional ou nas de ordem democrático-liberal houve um ir e vir de escolhas que não fornecem um só caminho a ser seguido, mas alguns caminhos.

$\mathrm{Na}$ questão 37 , pediu-se para que os alunos abordassem a formação e a implementação do Mercosul, conectando-o não só com a América Latina, mas com o mundo neoliberal.

A opção recorrente escolhida pelos alunos é a que concebe o Mercosul como associação entre países $(0,69)$, ou seja, visto por seu conceito estrutural. O item não é excludente, e por isso não tem um caráter opinativo, mas sim de uma espécie de reconhecimento neutro. Apesar de relativamente alto, o índice pode indicar que o conhecimento do que venha a ser o Mercosul não seja um dado garantido definitivamente entre os estudantes.

O segundo item de maior destaque é a tendência de concordância com a afirmação de que o Mercosul é a melhor opção frente às imposições da contemporaneidade e perante os outros blocos econômicos. Novamente, prioriza-se a questão econômica, contudo, em uma análise mais ampla por contemplar na resposta a ordem global.

A noção de Mercosul como tendo sua origem na integração histórica dos países que o compõem forneceu índices negativos, ou seja, com uma leve tendência a discordar da assertiva, o que indica que o foco pelo qual provavelmente esses países estão pensados é o foco da História nacional, e não da região que envolve o bloco. Nada mais natural, na medida em que são escassas as iniciativas nesse sentido no campo do ensino de História nas escolas, bem como no campo das trocas culturais entre os países em questão.

O Mercosul como desvantajoso foi uma consideração em média rechaçada pelos respondentes. Nessa mesma linha, também não acreditam que o bloco latino-americano seja pior para seu país e meIhor para os outros. Desse modo, nota-se que o individualismo se dá quanto ao passado dos países que compõe tal bloco, pois, quando a pergunta volta-se para o presente surge a ideia de que é vantajoso aos seus membros, ainda que esse vantajoso seja abordado, primordialmente, pelo aporte econômico. Essa consideração permite arriscar que, para o futuro, há 
alguma abertura, em termos de concepções, para uma concepção de país que envolva seus parceiros mais próximos.

Em todas essas considerações, a opinião dos jovens uruguaios é consistente e mais marcada ou intensa. Argentina e Brasil, por sua vez, apresentaram índices próximos entre si; a rejeição da integração pelos motivos históricos registrou na Argentina a maior discordância. Assim, Brasil e Argentina (segundo os alunos) são beneficiados pelo Mercosul no que tange ao desenvolvimento econômico, contudo, esses benefícios não são associados aos demais prismas de vantagens que advêm da integração, talvez pela questão comercial ser a mais desenvolvida até agora entre os países membros.

Outro questionamento é o quanto os alunos conhecem da História dos países vizinhos, para avaliar o papel do passado na integração presente. O Uruguai apresenta ponderações similares de modo geral, diferenciando-se pelos valores mais expressivos nas concordâncias e discordâncias, o que parece indicar concepções mais nítidas em relação ao bloco.

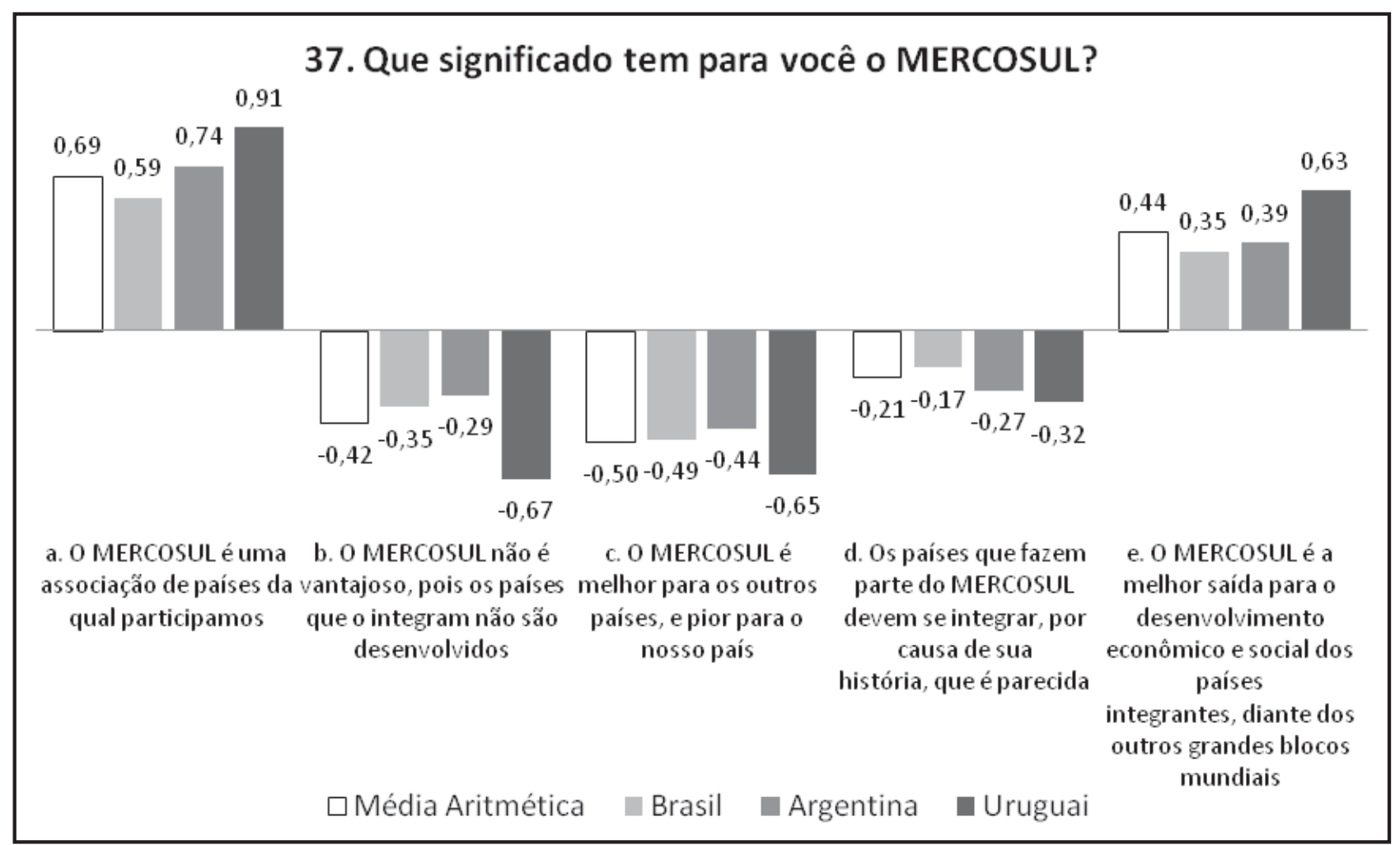

Figura 4. Questão 37 do Questionário

Fonte: Dados do Projeto Jovens diante da História - 2009

\section{Considerações Finais}

Os objetivos iniciais, ou seja, as questões de consciência histórica que envolvem passado, presente e futuro e atreladas às noções de identidade foram nitidamente observadas tanto nos enunciados quanto nas opções dos alunos pesquisados. A amplitude da pesquisa, isto é, Brasil, Argentina e Uruguai (ainda que as amostras sejam pequenas), colaborou para a visualização de aspectos congruentes e divergentes entre esses países, explicitando que a ordem mundial tem suas nuances, diante das características próprias de cada nação, evidenciadas com intensidade nas opções escolhidas.

Atenta-se para o fato de que ao mudar o foco de questionamento nos enunciados as respostas se tornaram, em alguns momentos, paradoxais. Enfatizar que o conflito em Terranova deveria ser solucionado por uma reunião internacional em nada se aproxima da defesa de seu país por todos os meios possíveis (formulação pela qual se admite qualquer meio, inclusive o militar). Em outras palavras, quando a questão era direcionada a um país em geral, ocorreram tendências pacifistas, porém, quando o assunto envolvia seu país de origem provocava outra forma de entendimento, de viés tradicional.

Dentro do princípio de que há "contradição", nesse sentido, é algo que ainda não se consegue entender direito, pode-se estar diante de efeitos concomitantes do ensino de valores com consequências, no limite, divergentes (o nacionalismo e o pacifismo), ou as fórmulas quantitativas - tal qual 
aplicadas - não estão sendo suficientes para a compreensão do tema. Outra perspectiva possível na perseguição das hipóteses para esse tema é a dissociação entre a aprendizagem dos conceitos e a sua efetiva aplicação na vida cotidiana. Os alunos apreendem os conceitos de democracia e blocos político-econômicos, por exemplo, mas é escasso o transporte para a prática ou a concepção das diversas faces e contexto em que se inserem.

O Mercosul, apesar da grande veiculação pelos meios midiáticos, parece ser ainda mal conhecido e definido. A tendência é compreendê-lo pelo seu aspecto mais "burocrático", como simples associação entre países derivada do pragmatismo frente aos obstáculos da contemporaneidade. A perspectiva histórica e cultural que defende que o cerne do bloco, ou seja, a integração decorrente de um passado em comum ainda é um mito para os alunos. Questionamos até que ponto essa opinião é fundada no suficientemente conhecimento da História dos países vizinhos. Esse dado indica a retomada de uma discussão sobre o ensino de História dos demais países da América, obviamente por um viés diferente daquele dos acordos dos anos 1930 ou 1950 (esses motivados pelo pan-americanismo do contexto da Guerra Fria).

A noção histórica de passado tende a ser deslocada do todo para o particular: os pesquisados denotaram com grande objetividade que o fator "passado" associa-se primordialmente ao seu país. A América Latina aglutinadora só vem a existir de um presente para um possível futuro, ainda assim, preponderantemente pelo viés econômico. Esse dado indica um provável resultado da marca de nascença que é a educação histórica provida pela escola, ou seja, a sua nacionalidade, em contraposição à "História Geral". As duas esferas continuam demonstrando dificuldades de concatenação, e essas dificuldades se intensificam para a História regional do subcontinente, que não é nem nacional, nem geral.

As peculiaridades de cada país se evidenciaram. Por exemplo, Argentina e Uruguai ressaltam mais fortemente os caracteres identitários e culturais que formaram sua nacionalidade e, ainda assim, os uruguaios apresentam respostas mais calorosas, decididas, pois as médias registradas apontam geralmente para valores maiores que os de estudantes argentinos e brasileiros, seja nos resultados negativos, seja nos positivos.

O caso brasileiro demonstra menor rejeição frente às opções militaristas, o que não significa apoiá-las, mas, talvez, maior superação das marcas das ditaduras militares que assolaram por décadas a América Latina. Evidentemente que essa superação pode estar ocorrendo pela amnésia, em vez da resolução das pendências em termos de direitos humanos, deixadas pela ditadura. Os ideais democráticos e a politização estão mais diluídas nas respostas dos alunos brasileiros, o que pode ser reflexo de um processo tardio - e ainda em curso - de escolarização maciça da população, que no Uruguai e na Argentina aconteceu já no século $X I X$.

O repúdio a noções mecanicistas e estreitas demonstra o quanto provavelmente se modificaram a consciência histórica e a cultura política, ainda mais em comparação a países tidos como de Primeiro Mundo pela ordem econômica global, nos quais o militarismo e as tendências belicistas muito se assemelham ao panorama do século XIX imperialista.

As marcas da colonização também se fazem presentes, principalmente nas áreas sociocultural e econômica. As feridas mal cicatrizadas podem ser notadas em escolhas que atribuem ao passado à falta de integração ou classes sociais estigmatizadas. Em contrapartida, tem-se também já uma noção de Estado enquanto ente gestor, responsável pelas temporalidades históricas e com maior independência, além de uma visão global quando se pensa em reuniões e tratados internacionais.

Desse modo, evidenciam-se alunos em formação, porém, que refletem todo um passado colonial e marcas recentes do pensamento neoliberal, sem saber ao certo o que esperar do futuro. O conjunto contextual e as diretrizes colocadas pela contemporaneidade fornecem um ir e vir incessante de afirmações e representações, variando conforme a pergunta e os valores que ela agrega.

O posicionamento da América Latina enquanto região em crescimento e a recente História política de cunho autoritário dos países, em grande medida, colaboram para o ir e vir de pensamentos e respostas - e é exatamente nesse ponto que esse artigo e o projeto "Jovens e História" vêm a atuar, na articulação entre passado/presente/futuro, suas lacunas, dilemas e paradigmas.

\section{Referências}

ABREU, M.; SOIHET, R.; GONTIJO, R. (Orgs.). Cultura política e leituras do passado: historiografia e ensino de história. Rio de Janeiro: Civilização Brasileira/FAPERJ, 2007.

ANGVIK, M; BORRIES, B. Youth and history: a comparative european survey on historical consciousness and political attitudes among adolescents. Hamburg: KörberStiftung; Heinrich-Heine-Buchh, 1997.

BAUMAN, Z. Identidade. Rio de Janeiro: Zahar, 2005.

BORBA, J. Cultura política, ideologia e comportamento eleitoral: alguns apontamentos teóricos sobre o caso brasileiro. Opinião Pública, Campinas, v. 11, n. 1, p. 147168, mar. 2005. 
CARDOSO, O. Para uma definição de didática da história. Revista Brasileira de História, São Paulo, v. 28, n. 55, p. 153-170, 2008.

CERRI, L. F. Os conceitos de consciência histórica e os desafios da didática da história. Revista de História Regional, Ponta Grossa, v. 6, n. 2, p. 93-112, 2001.

FLORES, E. C. Dos feitos e dos ditos: História e cultura histórica. Saeculum - Revista de História, João Pessoa, n. 16, p. 83-102, jan./jun. 2007.

GUYON, S.; MOUSSEAU, M. J.; TUTIAUX-GUILLON, N. Desnations à la nation: apprendre et conceptualiser. Paris: INRP, 1993

JOHNSON, A. G. Dicionário de sociologia. Rio de Janeiro: Zahar, 1997.

HALL, S. A identidade cultural na pós-modernidade. 3. ed. São Paulo: DP\&A, 1999.

IANNI, O. O estado-nação na época da globalização. Econômica, Rio de Janeiro, v. 1, n. 1, p. 105-117, jun. 1999.

MOISÉS, J. A. Democratização e cultura política de massas no Brasil. Lua nova, São Paulo, n. 26, p. 5-51, 1992.

POUTIGNAT, P.; STREIFF-FENART, J. Teorias da etnicidade. São Paulo: UNESP, 1998.

RENAN, E. O que é uma nação? (Conferência realizada na Sorbonne, em 11 de março de 1882). Revista Aulas, Campinas, n. 1, p. 1-21, 2006. Disponível em: <http://www. unicamp.br/ aulas/VOLUME01/ernest.pdf>. Acesso em: 28 jun. 2010.

RÜSEN, J. Razão histórica - teoria da história: os fundamentos da ciência histórica. Brasília: Editora da UnB, 2001.

Recebido em 01/06/2010

Aceito em 06/08/2010 